\title{
DUCTILITY OF CONFINED CONCRETE MASONRY SHEAR WALLS
}

\author{
M.J.N. Priestley*
}

SUMMARY:

Calculations for the ductility capacity of unconfined concrete masonry shear walls developed in a previous paper are extended to cover the case of confined masonry shear walls. Design charts are presented which show that the available ductility will always be greater than three times the value for a corresponding unconfined wall. Recommendations to govern the required extent of confinement are made.

\section{INTRODUCTION}

In an earlier paper published in the Bulletinl aspects of the ductility of unconfined concrete masonry shear walls were discussed. From consideration of the low ultimate compression strain, and geometric constraints, it was shown that many concrete masonry shear walls with moderate to high aspect ratio might have insufficient ductility capacity to satisfy levels implied by the Loadings code 2 , for the appropriate structural type factor.

The paper presented design charts to provide a simple means for checking ductility capacity of masonry walls. Suggestions were made as to possible courses of action where the design charts indicated that insufficient ductility was available. One of the options suggested was to place stainless steel confining plates in the mortar courses of the ultimate compression zones within the potential plastic hinge regions at the wall base. It was indicated that the increased ultimate compression strain resulting from the effects of confinementwould substantially increase the ductility capacity of a given masonry shear wall, but no quantitative assessment of the increased dutility was made. This paper redresses the omission, by considering the ductility capacity of confined walls, presenting the results in the form of design charts of similar format to those prepared for unconfined walls in the earlier paper. The procedure adopted closely follows that used in the earlier paper, and to avoid unnecessary duplication, considerable reference to reference $I$ will be made.

\section{STRESS-STRAIN CURVES FOR CONFINED}

\section{CONCRETE MASONRY}

Fig. I of reference I showed theoretical stress-strain curves for unconfined and confined concrete masonry, plotted for $f_{m}^{\prime}=16 \mathrm{MPa}$. These curves were based on results of a recent masonry prism test programme ${ }^{3}$. Confinement consisted of 3. lmm thick stainless steel plates within the mortar beds cut to the net shape of the masonry units so that there was no interference with the grout flues, and with a $5 \mathrm{~mm}$ edge allowance for pointing. Fig. I (this paper) gives the plate dimensions, and shows a confining plate in a prism under construction. A comparison between theoretical and experimental curves is

*Reader in Civil Engineering, University of Canterbury, New Zealand.

BULLETIN OF THE NEW ZEALAND NATIONAL SOCIETY FOR EARTHOUAKE ENGINEERING, VOL. 15, NO. 1, MARCH 1982 shown for both unconfined and confined masonry prisms in Fig. 2 .

The theoretical curve used for confined masonry, and shown in Fig. 2 is the modified Kent-Park curve for confined concrete 4 , described by the following equations.

(1)

$$
\begin{aligned}
& \text { (1) for } \varepsilon_{\mathrm{m}} \leq 0.002 \mathrm{~K} \\
& f_{\mathrm{m}}=\mathrm{K} \cdot \frac{\mathrm{f}_{\mathrm{m}}^{\prime}}{0.9375}\left[\frac{2 \varepsilon_{\mathrm{m}}}{0.002 \mathrm{~K}}-\left(\frac{\varepsilon_{\mathrm{m}}}{0.002 \mathrm{~K}}\right)^{2}\right] \text { (1) } \\
& \text { where } \mathrm{K}=1+\rho_{\mathrm{s}} \frac{\mathrm{yh}}{\mathrm{f}_{\mathrm{m}}^{\prime}} \\
& \rho_{\mathrm{s}}=\underset{\text { volumetric ratio of confining }}{\text { steel }} \\
& \mathrm{f}_{\mathrm{yh}}=\text { confining steel yield strength } \\
& \text { (2) } 0.002 \mathrm{~K}<\frac{\varepsilon_{\mathrm{m}} \leq 0.008}{\mathrm{~K}} \mathrm{f}_{\mathrm{m}}^{\prime}\left[1-z_{\mathrm{m}}\left(\varepsilon_{\mathrm{m}}-0.002 \mathrm{~K}\right)\right] \text { (3) } \\
& \mathrm{f}_{\mathrm{m}}=\frac{0.9375}{0.9375}
\end{aligned}
$$

where

$$
\begin{aligned}
& z_{m}= 0.5 \\
& \text { and } h^{\prime \prime}= \begin{array}{l}
\text { lateral dimension of the } \\
\text { confined core (i.e. block } \\
\text { width) }
\end{array} \\
& S_{h}=\begin{array}{l}
\text { spacing of confining steel } \\
\text { (i.e. block unit height) }
\end{array}
\end{aligned}
$$

The ultimate strain of $\varepsilon_{\mathrm{m}}=0.008$ is taken to be a conservative limit based on the results of the test programme ${ }^{3}$. The 0.9375 denominator in Eqs. 1 and 3 results from the premise, adopted in ref. 1 , that the unconfined crushing strength $f_{m}^{\prime}$ results from premature vertical splitting at a strain of 0.0015 . The unconfined curve is defined by a parabolic curve with a fictitious maximum stress of $\mathrm{f}_{\mathrm{m}}$

$$
\overline{0.9375}
$$

occurring at a strain of 0.002 . This

gives the correct value of $\mathrm{f}_{\mathrm{m}}^{\prime}$ at $\varepsilon_{\mathrm{m}}=0.0015$. 


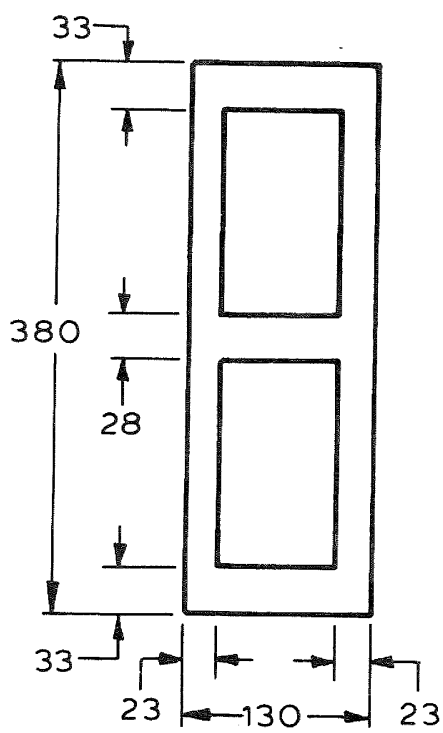

(a) Dimensions
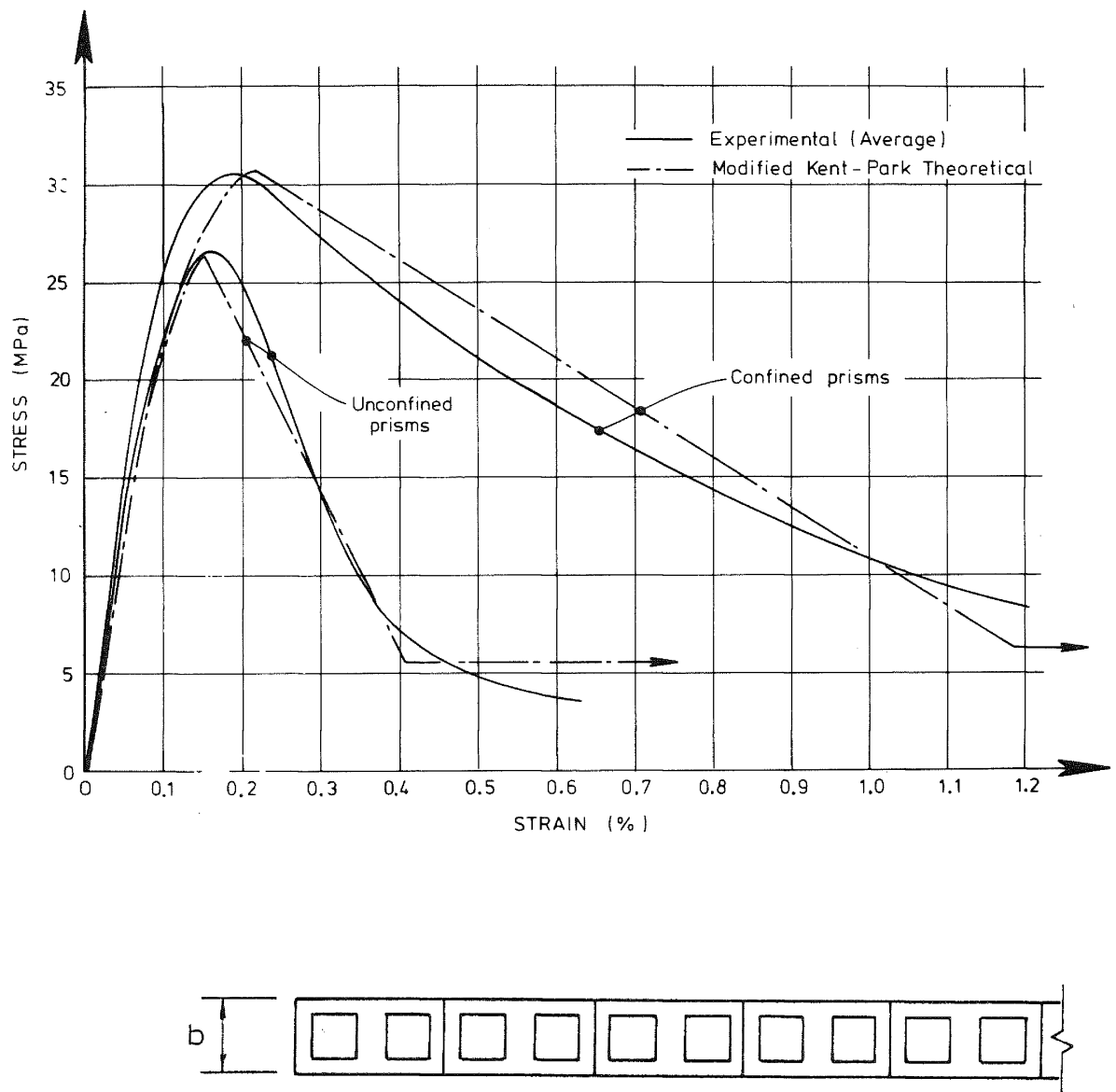

(a) Wall Section

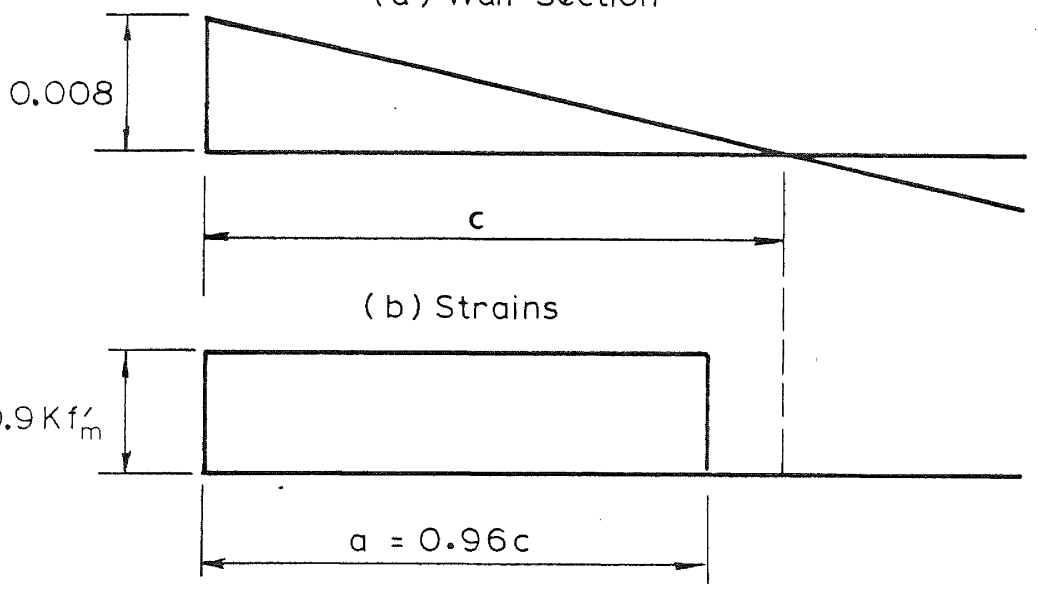

(c) Equivalent Stress Block
FIG 1 - CONFINING PLATES FOR CONCRETE MASONRY PRISMS

(3.1 mm Stainless Steel Type 304)
FIG 2 - THEORETICAL AND EXPERI. MENTAL STRESS-STRAIN CURVES FOR CONCRETE MASONRY PRISMS
FIG 3 - EQUIVALENT RECTANGULAR STRESS BLOCK FOR CONFINED CONCRETE MASONRY 
Confining plates inhibit the formation of vertical splitting, and thus maximum stress occurs at a strain of $\varepsilon_{\mathrm{m}}=0.002 \mathrm{~K}$, as for confined concrete.

\section{DUCTILITY CAPACITY}

\section{Conditions at First Yield}

Using the confined stress-strain curve results in small changes to the equations developed in Ref. 1 . Examination of the requirements of static equilibrium shows that Eqn. (7) of reference 1 becomes

$$
\begin{aligned}
& 2\left(\frac{f_{m}^{\prime}}{0.9375 f_{y}} \cdot \frac{\varepsilon_{y}}{0.002}\right) k_{e}^{2}\left(1-\frac{k_{e}}{1-k_{e}}\right)\left(\frac{\varepsilon_{y}}{0.006 \mathrm{~K}}\right)+ \\
& 2\left(\rho+\frac{N_{u}}{b_{l_{w} f_{y}}}\right) k_{e}-\left(\rho+\frac{2 N_{u}}{b l_{w} f_{y}}\right)=0
\end{aligned}
$$

where $k_{e}=c_{e} / l_{w}$ is the proportion of the wall length in compression at yield, and applies for $\varepsilon_{\mathrm{m}}<0.002 \mathrm{~K}$, where $\mathrm{K}$ is defined by Eqn. (2). The dimensionless form of the yield moment, $\mathrm{m}_{\mathrm{y}}$, becomes $m_{y}=\frac{f_{m}^{\prime}}{\left(0.9375 f_{y}\right)} \cdot k_{e}^{2} \cdot \frac{\varepsilon_{m}}{0.002}\left(\frac{2}{3}-\frac{\varepsilon_{m}}{0.008 K}\right)+$ $\frac{k_{e}{ }^{3}}{3\left(1-k_{e}\right)} \rho+\frac{\left(1-k_{e}\right)^{2}}{3} \rho+\frac{N_{u}}{b l_{w} f_{y}}\left(\frac{1}{2}-k_{e}\right)$

\section{Conditions at Ultimate}

It is not sufficiently accurate to use the ACI stress block to represent the shape of confined concrete masonry, with an ultimate compression strain of $\varepsilon_{=}=0.008$, and stress-strain characteristics deffined by equations (1) to (3). Since the extent of strength enhancement and the slope of the falling branch of the stress-strain curve are both dependent on the masonry strength $f_{m}^{\prime}$ for a given quantity of confining steel, different curves should be used. However, for $\rho_{s}=0.00766$ corresponding to $3.1 \mathrm{~mm}$ thick confining plates, and $f_{y h}=316 \mathrm{MPa}$, which were the values pertaining to the experimental study ${ }^{3}$, it was found that the equivalent stress block given in Fig. 3 could be used with sufficient accuracy for the range of strengths $8 \mathrm{MPa} \leq \mathrm{f}_{\mathrm{m}}^{\prime} \leq 32 \mathrm{MPa}$. In terms of conventional reinforced concrete analysis, the masonry compression force is thus

$$
C_{m}=0.9 K f_{m}^{\prime} a b
$$

where $\quad a=0.96 c$

Equation 6 underestimates the masonry compression force by $7 \%$ for $f_{m}^{\prime}=8 \mathrm{MPa}$ and overestimates it by $6 \frac{1}{2} \%$ for $f_{m}^{\prime}=32 \mathrm{MPa}$.

The neutral axis position, modified from Eq. (10) of reference 1 now becomes

$k_{u}=\frac{c_{u}}{l_{w}}=\frac{\left(\rho+\frac{N_{u}}{b_{l_{w}} \cdot f_{y}}\right)}{\left(0.864 \frac{K_{m}^{\prime}}{f_{y}}+2 \rho\right)}$ and the dimensionless ultimate moment, found by taking moments about the neutral axis, is thus

$$
\begin{aligned}
& m_{u}=0.449 k \cdot k_{u}{ }^{2} \frac{f_{m}^{\prime}}{f_{y}}+\frac{\rho}{2}\left(k_{u}{ }^{2}+\left(1-k_{u}\right)^{2}\right)+ \\
& \frac{N_{u}}{b l_{w^{\prime}} f_{y}}\left(\frac{1}{2}-k_{u}\right)
\end{aligned}
$$

The ultimate curvature will be

$\phi_{\mathrm{u}}=\frac{0.008}{\mathrm{k}_{\mathrm{u}} \cdot \mathrm{l}_{\mathrm{w}}}$

Equations (4) to (9) above can now be used in conjunction with Eqns. (9), (15) and (17) of reference 1 to predict the displacement ductility capacity of any confined rectangular concrete masonry shear wall. A sensitivity analysis duplicating the range of variables considered for unconfined walls was carried out by computer.

\section{RESULTS}

Figs. 4 and 5 give ductility capacities of unconfined walls of true aspect ratio $A_{T}=3$ for $f_{Y}=275 \mathrm{MPa}$ and $f_{\mathrm{Y}}=380 \mathrm{MPa}$ respectively. For completeness, the correction factor for walls of true aspect ratios other than $A_{T}=3$ is duplicated from Fig. 8 of reference 1 , and shown in Fig. 6.

Again it has been possible to express all $\mu_{3}$ values for a given reinforcement yield strength on a single graph using the variables

$\mathrm{N}_{\mathrm{u}} / \mathrm{f}_{\mathrm{m}}^{\prime A g}$ where $\mathrm{Ag}=\mathrm{b} \cdot \mathrm{l}_{\mathrm{W}}$, and $\rho^{\prime}=\frac{10.42}{\mathrm{~K} f_{\mathrm{m}}^{\prime}}$.

In fact, the curves are not strictly dimensionless as the yield curvature and moment depend on the confinement factor $\mathrm{K}$, which is a function of $f_{m}^{\prime}$. However,

the error is small, and is significant only for high values of $f_{m}^{\prime}$ and

$\frac{\mathrm{N}_{\mathrm{u}}}{\mathrm{f}_{\mathrm{m}}^{\mathrm{Ag}}}$ (an unlikely combination), when errors in $\mu_{3}$ up to about $6 \%$ may be expected. Note that Figs. 4 and 5 apply for $\rho_{S}=0.00766$ and that the value 10.42 in the expression for effective reinforcement ratio comes from

$$
8 \mathrm{MPa} \mathrm{x} \mathrm{K}_{8}=10.42
$$

$$
\text { where } \begin{aligned}
\mathrm{K}_{8}= & 1+\rho_{\mathrm{s}} \cdot \frac{\mathrm{f}_{\mathrm{yh}}}{\mathrm{f}_{\mathrm{m}}^{\top}} \\
= & 1+0.00766 \times \frac{316}{8} \\
= & 1.303 \text { is the confinement factor } \\
& \text { for } \mathrm{f}_{\mathrm{m}}^{\prime}=8 \mathrm{MPa} .
\end{aligned}
$$

The trends apparent in Figs. 4 and 5 parallel those for unconfined walls, but with higher ductilities available for corresponding confined walls. Available ductility decreases as the reinforcement ratio and yield strength increase, as 


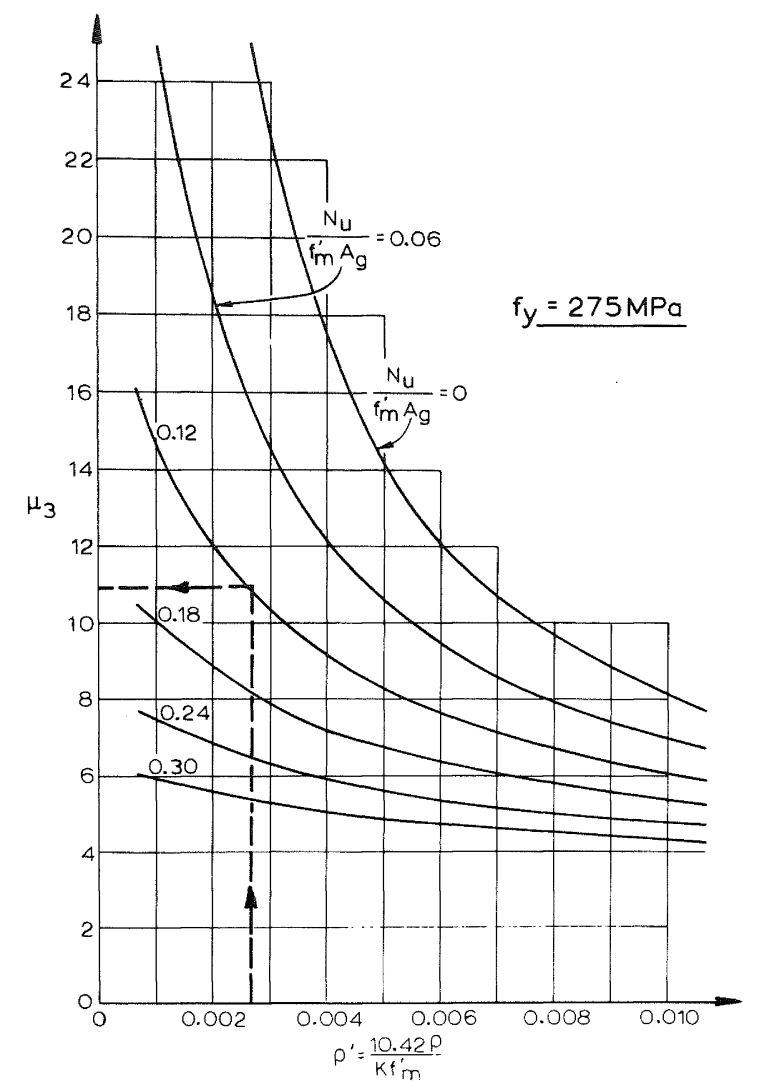

FIG. 4 - DUCTILITY OF CONFINED MASONRY WALLS FOR ASPECT RATIO $A_{T}=3\left(f_{y}=275 \mathrm{MPa}\right)$

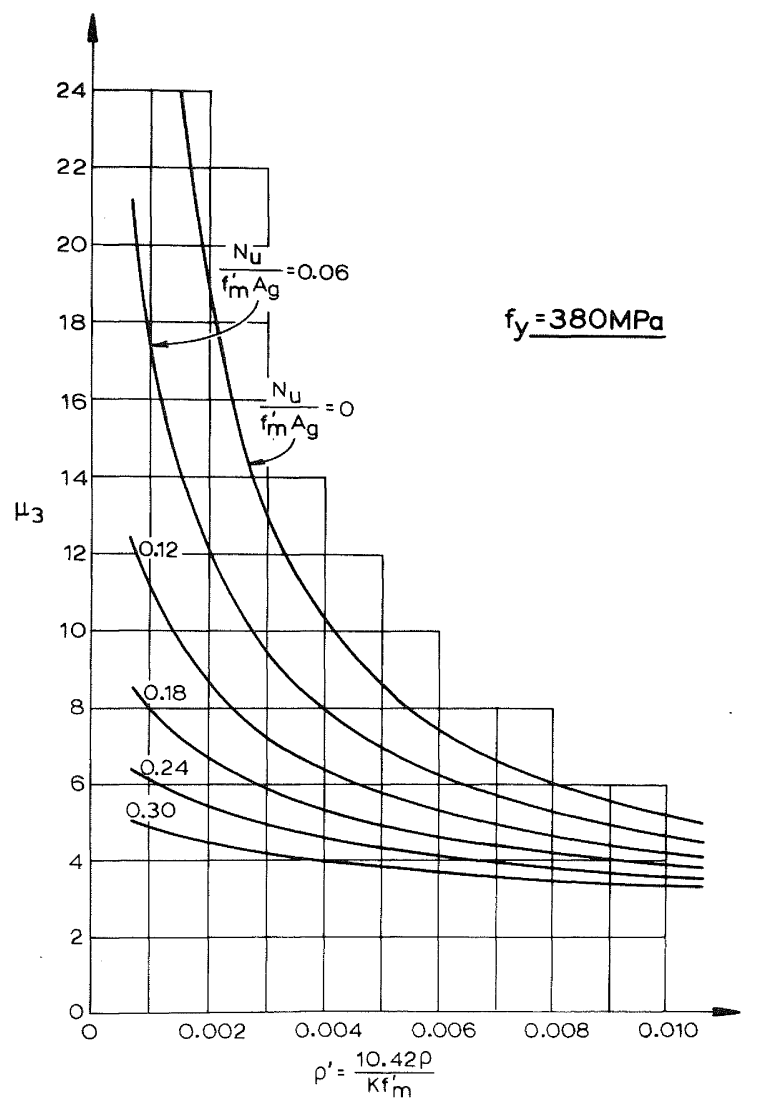

1G. 5 - DUCTILITY OF CONFINED MASONRY WALLS FOR ASPECT RATIO $A_{T}=3\left(f_{Y}=380 \mathrm{MPa}\right)$

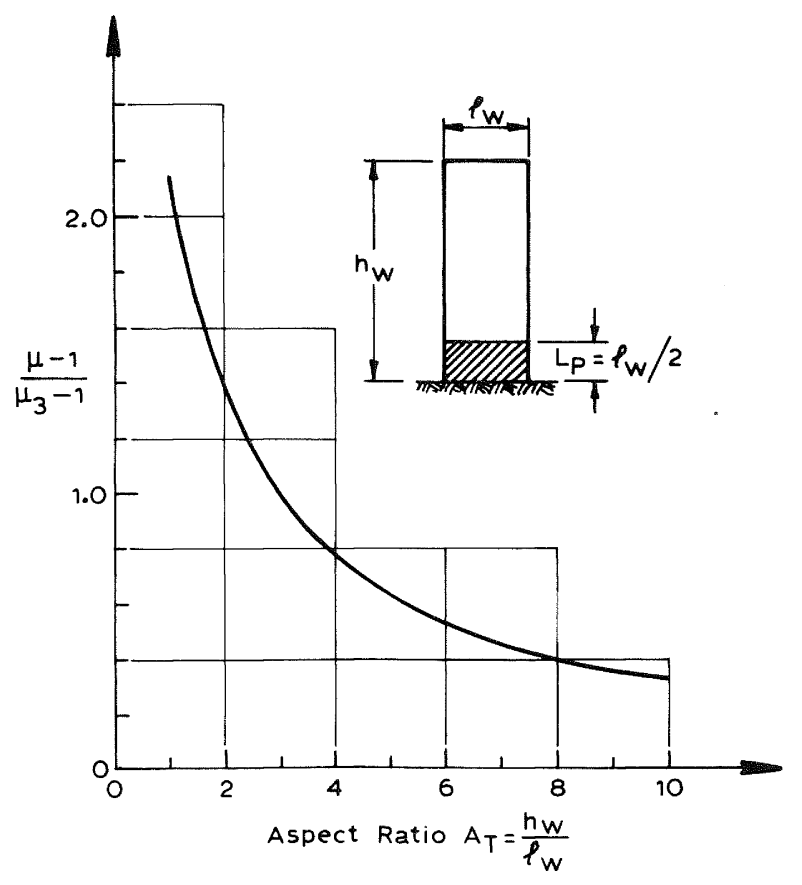

FIG. 6 - CORRECTION FACTOR FOR WALL ASPECT RATIO (Related to $A_{T}=3$ as datum) From Ref. 1 
axial load level increases, and as crushing strength decreases.

In reference 1 , use of the charts was illustrated by an example wall of height $16 \mathrm{~m}$, length $4 \mathrm{~m}$ and thickness $190 \mathrm{~mm}$, reinforced by Dl6 bars $\left(f_{y}=275 \mathrm{MPa}\right.$ ) at $400 \mathrm{~mm}$ crs, giving a steel ratio of $\rho=0.00264$. Masonry crushing strength was set at $\mathrm{f}_{\mathrm{m}}^{\prime}=8 \mathrm{MPa}$, and an axial load of $\mathrm{N}_{\mathrm{u}}=720 \mathrm{kN}$ was applied at the plastic hinge.

The unconfined wall had a predicted ductility capacity of

$$
\mu=2.41 \text {. }
$$

As this was insufficient, it was recommended that either the masonry strength be increased to $16 \mathrm{MPa}$, giving a ductility capacity of $\mu=4.6$, or the critical mortar beds in the compression zone of the plastic hinge be confined. From Fig. 4, we can now check the effectiveness of the later alternative. Since the unconfined crushing strength is $8 \mathrm{MPa}, \rho^{\prime}=.00264$ as for the unconfined wall. With the axial load ratio at $\mathrm{N}_{\mathrm{u}} / \mathrm{f}_{\mathrm{m}}^{\mathrm{Ag}}=0.118, \mathrm{Fig} .4$ gives the displacement ductility factor related to an aspect ratio of $\mathrm{A}_{\mathrm{T}}=3$ as

$$
\mu_{3}=10.9 \text {. }
$$

From Fig. 6, the correction factor for $A_{T}=4.0$ is

$$
\frac{\mu_{4}-1}{\mu_{3}-1}=0.795
$$

$$
\text { Hence } \mu_{4}=8.9
$$

This ductility is more than sufficient to satisfy requirements implied by the loadings code ${ }^{2}$. If this alternative, rather than increasing the masonry compression strength, was adopted, there would be no requirement to perform prism testing. The correct solution would result from consideration of the relative costs and difficulties of masonry prism tests compared with the use of confining plates.

\section{CONCLUSIONS}

Use of confining plates will always increase the ductility capacity of a given concrete masonry shear wall by a factor of at least three. It is felt that in many cases the use of a few confining plates in critical locations will be a more effective, and preferable solution to increasing the design level of masonry compression strength to a value that may be difficult to attain in the field. Consequently some guidelines for extent of confinement are required. The guidelines suggested below are based on the observed behaviour of three tall masonry shear walls tested as part of the masonry test program reported in reference 3 . should correspond to the height of the potential plastic hinge zone. Generally this will imply confinement for a height equal to the wall length $\ell_{w}$. This requirement is probably conservative. Recent testing ${ }^{3}$ of a wall confined to a height of only $0.58 l_{w}$ indicated satisfactory performance, though extreme fibre compression strains immediately above the confined extent were close to the unconfined ultimate strain of $\varepsilon_{\mathrm{u}}=0.0025$.

(b) The horiztonal extent of confinement should not be less than that region from the extreme compression fibre to the position $70 \%$ of the distance to the theoretical neutral axis position at ultimate, nor less than $600 \mathrm{~mm}$. Covering the most highly strained $70 \%$ of the compression zone ensures that no unconfined fibres are subjected to strains in excess of 0.0025 . The minimum length of $600 \mathrm{~mm}$ is intended to ensure that the end two vertical flues, and any reinforcement they contain, are tied back into the body of the wall, minimizing the influence of weak header joints close to the extreme compression fibre.

\section{REFERENCES :}

1. Priestley, M.J.N., "Ductility of Unconfined Masonry Shear Walls", Bulletin, NZNSEE, Vol. 14, No. 1, March 1981, pp.12-20.

2. "Code of Practice for General Structural Design and Design Loadings for Buildings", NZS 4203:1976. S.A.N.Z., Wellington, 1976, 104 pp.

3. Priestley, M.J.N. and Elder, D.M., "Seismic Behaviour of Slender Masonry Shear Walls", Dept. of Civil Engineering, University of Canterbury, Research Report (to be published).

4. Park, R., Priestley, M.J.N., and Gill, W.D., "Ductility of Square Confined Reinforced Concrete Columns", Journal ASCE, Structural Div., Vol. 108, STll, April 1982.

\section{Extent of Confinement}

